\title{
Aposentar-se ou Continuar Trabalhando? O que Influencia essa Decisão?
}
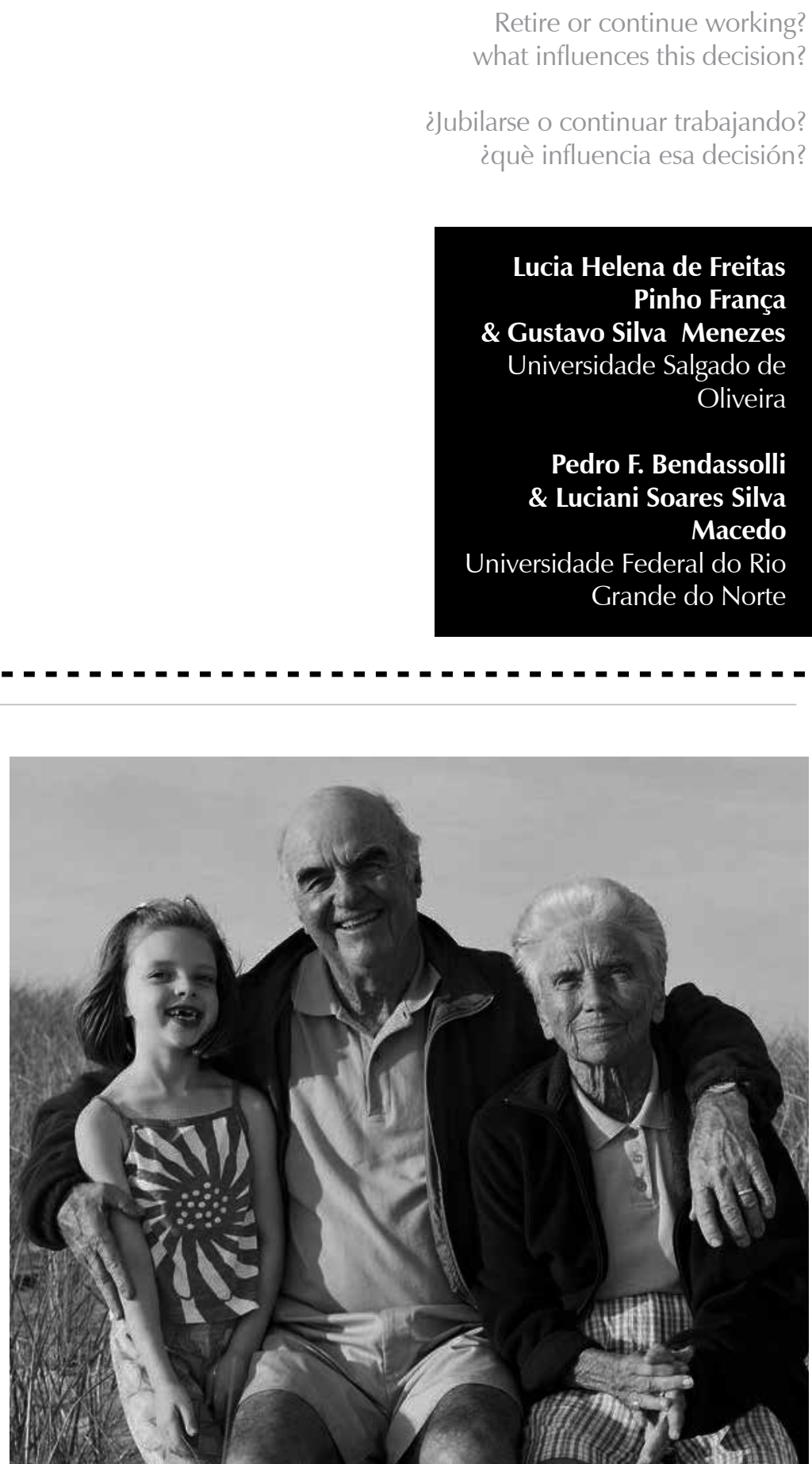
Resumo: O aumento da população idosa é um dos fenômenos mais notáveis nos últimos tempos, e vem ocorrendo tanto nos países centrais quanto nos periféricos. Esse novo cenário demográfico provocou diversas mudanças em todos os setores da sociedade, inclusive nas organizações. Nesse sentido, alguns pesquisadores vêm estudando as variáveis que podem influenciar a decisão trabalho-aposentadoria. Este estudo discute os aspectos que podem fazer aumentar a permanência dos trabalhadores na organização, sua saída definitiva do mercado ou a adoção do bridge employment (o emprego que tem vez após o rompimento com a estrutura formal do trabalho). São analisados os aspectos individuais (idade, percepção de saúde, expectativa subjetiva de vida, situação e relacionamento familiar e status financeiro), aspectos de trabalho (percepção e controle do trabalho, flexibilidade de horário) e a preparação para a aposentadoria, que podem influenciar a decisão desses trabalhadores. Por fim, discutem-se os limites e as possibilidades de transposição dos achados de pesquisas estrangeiras sobre a decisão de aposentadoria para o contexto brasileiro, e são apresentados alguns desafios para a gestão da aposentadoria no Brasil.

Palavras-chave: Envelhecimento. Tomada de decisão. Aposentadoria. Trabalho. Recursos humanos.

Abstract: The increase on the elderly population is a most notable phenomena in recent years, and it has been occurring as much as in central countries, as in peripheral countries. This new demographic scenario has provoked a number of changes in all sectors of society, including organizations. As such, some researchers have been studying the factors that can influence the decision retirement-work. This study discusses the different aspects that may influence the workers' decision to continue in the organization, their definitive step out of the market, or the adoption of a bridge employment (employment after the rupture with the formal working structure). The individual aspects are analysed (age, health perception, subjective expectancy of life, situation in family relationships and financial status), as well as the working aspects (work perception and control, flexibility in schedule), and the preparation for retirement, that may influence the decision of these workers. Finally, the limits and possibilities of transferring findings of international-based research to Brazilian reality are discussed, and some challenges regarding how to deal with retirement issues in Brazil are also presented.

Keywords: Ageing. Decision making. Retirement. Work. Human resources.

Resumen: El aumento de la población de ancianos es uno de los fenómenos más notables en los últimos tiempos, y viene ocurriendo tanto en los países centrales como en los periféricos. Ese nuevo escenario demográfico provocó diversos cambios en todos los sectores de la sociedad, incluso en las organizaciones. En ese sentido, algunos investigadores vienen estudiando las variables que pueden influenciar la decisión trabajo-jubilación. Este estudio discute los aspectos que pueden hacer aumentar la permanencia de los trabajadores en la organización, su salida definitiva del mercado o la adopción del bridge employment (el empleo que viene después del rompimiento con la estructura formal de trabajo). Son analizados los aspectos individuales (edad, percepciones de salud, expectativa subjetiva de vida, situación y relacionamiento familiar y status financiero), aspectos de trabajo (percepciones y control del trabajo, flexibilidad de horario) y la preparación para la jubilación, que pueden influenciar la decisión de esos trabajadores. Al fín, se discute las posibles formas de actuacion de los profesionales de Recursos Humanos en la coordinación de políticas que disminuan los impactos del envejecimiento demográfico, ya sea por la manutención de los trabajadores mayores, o por la actualizacion de ellos en las organizaciones.

Palabras claves: Envejecimiento. Tomada de decisión. Jubilación. Trabajo. Recursos humanos.

Os avanços da Medicina e da tecnologia têm exercido influência direta na longevidade da população mundial. Nos países desenvolvidos, esse avanço ocorreu durante mais de um século e de forma bem organizada. No Brasil, essa transformação ocorreu de forma muito rápida e, em poucas décadas, o País passou a enfrentar o desafio do envelhecimento. Por um lado, as melhores condições de saúde proporcionam o aumento da expectativa de vida e, portanto, de uma expansão da população idosa. Por outro lado, a taxa de natalidade vem retraindo-se ao longo dos últimos anos, o que ajudou a transformar a configuração da pirâmide etária (Organização das Nações Unidas, 2009; Fundo de População das Nações Unidas - UNFPA, 2012). 
O Instituto Brasileiro de Geografia e Estatística - IBGE (2008) ressaltou que, em 2050, o contingente de pessoas entre 70 e 80 anos será aproximadamente $40 \%$ maior do que a população entre 0 e 24 anos. Em termos absolutos, esse contingente representará, respectivamente, 71 milhões e 51 milhões de pessoas. Já a Pesquisa Nacional por Amostra de Domicílios (PNAD) demonstrou que, dos 195,2 milhões de brasileiros em 2011, 12,1\% tinham 60 anos ou mais de idade, somando 23,5 milhões de idosos, ou seja, mais que o dobro do registrado em 1991, que era de 10,7 milhões de idosos (IBGE, 2012). Em termos demográficos, o envelhecimento pode ser compreendido como um evento sofisticado, que reflete as mudanças na estrutura etária da população, em consequência da diminuição relativa da natalidade e do aumento dos idosos, como pode ser observado na Figura 1.
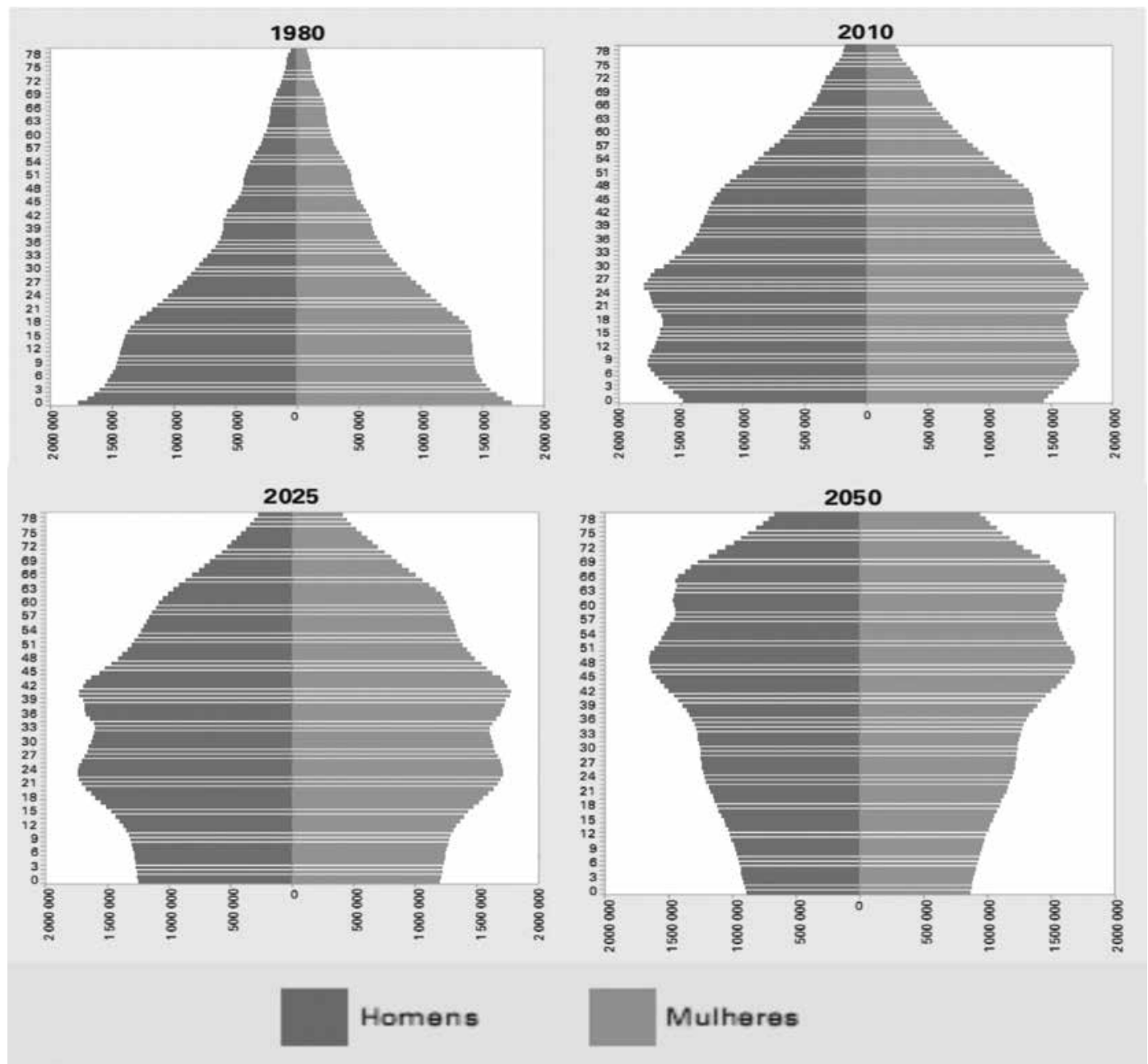

Figura 1. Pirâmide etária 1980 - 2010 - 2025 - 2050

Uma das consequências do envelhecimento populacional é o alto custo do pagamento das pensões e a sua sustentabilidade, sobretudo devido à inadimplência de muitas empresas e dos trabalhadores do mercado informal, cuja maioria não contribui para a Previdência. Além disso, nas últimas décadas, muitas pessoas têm se aposentado mais cedo, o que faz com que passem 
Outra consequência do envelhecimento populacional é observada no mercado de trabalho, em específico, na participação dos trabalhadores mais velhos na dinâmica ocupacional, que gera novas perspectivas e configurações

(Camarano, 2001; Flynn, 2010; França, 2012; Giatti \& Barreto, 2003). mais tempo aposentados do que trabalhando (França, 2008, 2012).

Outra consequência do envelhecimento populacional é observada no mercado de trabalho, em específico, na participação dos trabalhadores mais velhos na dinâmica ocupacional, que gera novas perspectivas e configurações (Camarano, 2001; Flynn, 2010; França, 2012; Giatti \& Barreto, 2003). Muitas organizações têm estimulado, por um lado, a permanência de profissionais altamente especializados, tendo em vista sua experiência e conhecimento acumulado; de outro, grande parte dos próprios trabalhadores, mesmo após atingir uma idade avançada, desejam continuar colaborando com o órgão/empresa em que trabalham, desde que estejam com as suas funções psíquicas e motoras em bom estado. Mas há trabalhadores que, não obstante esse cenário, desejam aposentar-se, tendo em vista a expectativa de passar mais tempo com a família, de dedicar-se ao lazer ou mesmo à realização de antigos sonhos. De fato, como aponta Rodrigues (2000), a aposentadoria representa um momento de maior liberdade e de desengajamento profissional, trazendo novas oportunidades e realizações.

Contudo, a aposentadoria pode também ser percebida como um período de desvalia e de diminuição da autoestima - que, por sua vez, leva ao sentimento de perda de status, de referências, do companheirismo entre os colegas de trabalho, ao sentimento de inutilidade e de perda financeira (Debetir \& Monteiro, 1999). Isso quer dizer que há várias representações relacionadas à aposentadoria, que levam a distintos posicionamentos das pessoas e, em consequência, a distintas decisões com respeito a continuar ou não no trabalho após o período em que podem escolher um caminho ou outro. Essas representações e, sobretudo, essas decisões, são influenciadas por classes distintas de fatores ou de variáveis psicossociais. A relevância que os trabalhadores atribuem aos ganhos e às perdas associados à aposentadoria, por exemplo, irão contribuir para as atitudes positivas ou negativas frente à transição por ela representada (França, 2008).

No campo da investigação empírica em Psicologia, diversos estudos têm sido realizados com o intuito de identificar os fatores que influenciam nas decisões relacionadas à aposentadoria, considerando ser esse um fenômeno complexo, multideterminado e dinâmico. A aposentadoria é também entendida como um processo, e não como um momento pontual no tempo e na dinâmica psicossocial das pessoas. Nesse sentido, Wang e Shultz (2010) destacam que há quatro perspectivas teóricas utilizadas por pesquisadores para discutir o processo e as consequências da aposentadoria: a perspectiva que a considera como um processo de tomada de decisão, como um processo de ajustamento, como uma fase de desenvolvimento da carreira e como um tema assumido como parte da gestão de recursos humanos.

Em específico no que diz respeito à perspectiva da aposentadoria como um processo de tomada de decisão, Feldman (1994) observa que se trata de um tipo de decisão que traz consequências de longo prazo, que implicam a reestruturação e a redução do comprometimento psicológico em relação ao trabalho e sua substituição progressiva por outras atividades, como familiares, comunitárias e de lazer, entre outras. Adicionalmente, como já mencionado, trata-se de um processo multideterminado. Assim, nesse ramo da literatura, o interesse tem se voltado para a identificação e o teste de diversos preditores empíricos envolvidos na decisão de aposentar-se ou de continuar no trabalho.

Este artigo segue trilha similar, tendo como objetivo explorar e revisar os principais 
preditores (empíricos) relacionados à i) decisão de aposentar-se em definitivo, ii) continuar trabalhando no mesmo trabalho, ou então de iii) adotar o modelo do bridge employment (tipo flexível de trabalho/ emprego adotado pela pessoa após sua aposentadoria). Para isso, realizou-se uma revisão dos estudos empíricos conduzidos nos últimos vinte anos, especialmente na literatura internacional.

O artigo está estruturado em três partes, além desta introdução. Na próxima parte, antes de entrar na discussão dos preditores propriamente ditos, são apresentados aspectos gerais e algumas definições relacionados ao processo de aposentadoria. Em seguida, são arrolados e discutidos os referidos preditores. O artigo segue então para sua última parte, de discussão e conclusões, na qual se discutem os limites e os cuidados na transposição de estudos estrangeiros para a realidade brasileira e são oferecidas algumas implicações para a gestão da aposentadoria na atualidade.

\section{O processo de aposentar-se: considerações gerais}

Um primeiro aspecto a considerar na decisão da aposentadoria é a idade em que essa decisão passa a fazer sentido. Para Adler e Hilber (2009), por exemplo, a decisão de continuar na força de trabalho ou de aposentar-se é tipicamente tomada entre 55 a 64 anos, e é influenciada por muitos fatores, nos quais também se inclui a disponibilidade dos empregos. Entretanto, uma vez que o processo de envelhecimento difere de pessoa para pessoa, é problemático tentar fixar uma idade específica para a aposentadoria. Em vez disso, é preciso explorar até que ponto os trabalhadores mais velhos podem ser contratados por diferentes indústrias e identificar os tipos de empregos e os fatores que melhor poderiam determinar a sua empregabilidade.
Outro ponto refere-se às preferências de regimes de trabalho após a aposentadoria, no caso de uma decisão pelo bridge employment. Rhum (1990) introduziu esse termo para categorizar qualquer trabalho remunerado após a aposentadoria, ou após o momento no qual o trabalhador começa a receber uma pensão. O bridge employment utiliza as estratégias de continuidade e a manutenção dos trabalhadores mais velhos ativos dentro ou fora da organização. Kim e Feldman (2000) apontam que, a partir do bridge employment, os trabalhadores podem ajustar gradativamente a sua retirada do mundo do trabalho, o que facilitaria a sua adaptação à aposentadoria e forneceria uma renda extra para complementar a pensão, bem como a oportunidade de estabelecer e de desenvolver novas rotinas que irão manter estruturada a vida do indivíduo. A flexibilização dos horários de trabalho, por meio de um tipo diferente de vínculo, pode ser uma alternativa para muitos, e envolve forma, benefícios e valores diferenciados.

Em alguns países, por exemplo, trabalhadores mais velhos desejariam continuar trabalhando em regime de meio período, de horário integral ou então por conta própria. Porém, entre eles, é raro o acúmulo da aposentadoria com o rendimento de outro trabalho (Feldman, 1994; Ruhm, 1990). No Brasil, essa situação é mais comum. Nessa direção, Camarano (2001) identificou que, em 1998, mais da metade dos homens idosos brasileiros e pouco mais de um terço das mulheres idosas que estavam trabalhando já eram aposentados. Além disso, sua pesquisa mostra que a maioria dos idosos pesquisados trabalhava na agricultura, e, deles, $60 \%$ trabalhavam mais de 40 horas semanais. Diante dessa constatação, seria interessante investigar as modalidades predominantes de trabalho pós-aposentadoria que têm sido observadas no Brasil, pois esse dado isolado parece preocupante, considerando carga horária e regime de trabalho, já que traz implicações para o equilíbrio entre a vida pessoal e a vida de trabalho (Stepansky \& França, 2008). 
Um terceiro ponto tem a ver com a complexidade do processo de decisão da aposentadoria. Feldman e Beehr (2011) observam que, embora tal decisão envolva um desfecho de tipo dicotômico, aposentar-se ou não, a decisão final sobre um ou outro caminho é direcionada por três avaliações interconectadas acerca da situação de trabalho ao longo do tempo: a primeira seria uma avaliação imaginativa sobre a possibilidade de aposentar-se no futuro; a segunda, quando se avalia o momento de deixar os antigos trabalhos, e a terceira, referente a colocar em ação, no presente, os planos concretos de aposentar-se. Para a compreensão da fase de imaginação do futuro, os autores sugerem considerar teorias como a das diferenças individuais, da identidade social e da autocategorização. Para a segunda fase, de avaliação do passado, sugerem a utilização das teorias dos estágios de carreira, as teorias sociais-normativas e a teoria do bridge employment. Na terceira fase, a de colocar os planos na prática, sugerem o embasamento em teorias de motivação.

Por fim, Feldman e Beehr (2011) reconhecem que, apesar de as teorias acima mencionadas desempenharem um papel importante na investigação sobre o processo de decisão relativo à aposentadoria, ainda há muito que se investigar nesse domínio. Os autores oferecem duas sugestões: a primeira, maior dedicação a estudos sobre traços de personalidade, que vão além da atual ênfase da literatura em questões relacionadas à saúde, às finanças e à idade. A segunda sugestão é que se dê mais atenção a estudos sobre desempenho no trabalho, já que estes podem ajudar a compreender porque trabalhadores mais velhos seriam mais relutantes em deixar o trabalho. As sugestões de Feldman e Beehr se somam às outras linhas de pesquisa encontradas na literatura e que serão descritas a seguir, que exploram mais diretamente a questão dos preditores empíricos envolvidos na decisão de aposentar-se.

\section{Preditores da tomada de decisão de aposentar-se}

A Tabela 1 apresenta os resultados de pesquisas sobre os preditores que podem influenciar a decisão da aposentadoria. Na sequência, discute-se cada um desses estudos e analisa-se sua importância para a compreensão de aspectos psicossociais envolvidos na decisão de aposentarse, de continuar a trabalhar ou de envolver-se em um bridge employment.

Tabela 1. Principais pesquisas sobre decisão de aposentadoria (2000 a 2012)

\begin{tabular}{|c|c|c|}
\hline Autores & Fonte & Preditores da decisão da aposentadoria \\
\hline Kim e Feldman (2000) & $\begin{array}{l}\text { Working in retirement: The } \\
\text { antecedents of bridge employment } \\
\text { and its consequences for quality of } \\
\text { life in retirement }\end{array}$ & $\begin{array}{l}\text { Percepção de saúde, status na organização, planejamento } \\
\text { financeiro, orientação prévia para a aposentadoria, estado } \\
\text { civil, satisfação pessoal, satisfação com o trabalho. }\end{array}$ \\
\hline Ulrich e Brott (2005) & $\begin{array}{l}\text { Older workers and bridge } \\
\text { employment: Redefining } \\
\text { retirement }\end{array}$ & $\begin{array}{l}\text { Características do trabalho, relações familiares, ocupação do } \\
\text { tempo, planejamento financeiro, rotina do trabalho. }\end{array}$ \\
\hline $\begin{array}{l}\text { Beehr, Glazer, Nielson } \\
\text { e Farmer (2000) }\end{array}$ & $\begin{array}{l}\text { Work and nonwork predictors of } \\
\text { employees' retirement ages }\end{array}$ & $\begin{array}{l}\text { Estar cansado de trabalhar, necessidade de cuidar de outra } \\
\text { pessoa, idade obrigatória de aposentadoria, expectativa de } \\
\text { trabalhar remuneradamente após a aposentadoria, expectativa } \\
\text { de participar de atividades consideradas de crescimento } \\
\text { (trabalho voluntário, atividades religiosas, cursos). }\end{array}$ \\
\hline $\begin{array}{l}\text { Wang, Zhan, Liu e } \\
\text { Shultz (2008) }\end{array}$ & $\begin{array}{l}\text { Antecedents of bridge employment: } \\
\text { A longitudinal investigation }\end{array}$ & $\begin{array}{l}\text { Idade, nível de educação, saúde percebida, status financeiro, } \\
\text { estresse no trabalho, satisfação no trabalho, estado civil, } \\
\text { qualidade do relacionamento, preparo para aposentadoria. }\end{array}$ \\
\hline $\begin{array}{l}\text { Shacklock e Brunetto } \\
\text { (2005) }\end{array}$ & $\begin{array}{l}\text { Employees' perceptions of the } \\
\text { factors affecting their decisions } \\
\text { to retire }\end{array}$ & $\begin{array}{l}\text { Finanças, motivação para o trabalho, saúde, condições de } \\
\text { trabalho flexíveis. }\end{array}$ \\
\hline
\end{tabular}


continuação da tabela 1

\begin{tabular}{|c|c|c|}
\hline Autores & Fonte & Preditores da decisão da aposentadoria \\
\hline $\begin{array}{l}\text { Pengcharoen e Shultz } \\
\text { (2010) }\end{array}$ & $\begin{array}{l}\text { The influences on bridge } \\
\text { employment decisions }\end{array}$ & $\begin{array}{l}\text { Fatores relacionados ao trabalho (envolvimento com o } \\
\text { trabalho e horário flexível), fatores não relacionados ao } \\
\text { trabalho (atitudes para aposentadoria, segurança dos planos } \\
\text { de aposentadoria, autoeficácia na busca por emprego) }\end{array}$ \\
\hline $\begin{array}{l}\text { Wang, Adams, Beehr } \\
\text { e Shultz (2009) }\end{array}$ & $\begin{array}{l}\text { Bridge employment and retirement: } \\
\text { Issues and opportunities during the } \\
\text { latter part of one's career }\end{array}$ & $\begin{array}{l}\text { Atributos individuais (idade, educação, saúde percebida } \\
\text { e status financeiro), ii) variáveis psicológicas e atributos do } \\
\text { trabalho (estresse e satisfação com o trabalho), iii) família (status } \\
\text { e qualidade) e iv) planejamento da aposentadoria (presença } \\
\text { ou ausência). }\end{array}$ \\
\hline $\begin{array}{l}\text { Zappalà, Depolo, } \\
\text { Fraccaroli, Guglielmi, } \\
\text { e Sarchielli (2008) }\end{array}$ & $\begin{array}{l}\text { Postponing job retirement? } \\
\text { Psychosocial influences on } \\
\text { the preference for early or late } \\
\text { retirement }\end{array}$ & $\begin{array}{l}\text { Idade cronológica, atitude negativa para aposentadoria, baixo } \\
\text { nível de informação sobre pensão, percepção de adequação } \\
\text { de renda financeira atual para aposentadoria, importância do } \\
\text { trabalho, trabalho com poucas demandas e que não exige o } \\
\text { desenvolvimento de competências adicionais, políticas em } \\
\text { prol do envelhecimento. }\end{array}$ \\
\hline $\begin{array}{l}\text { Solinge e Henkens, } \\
\text { (2009) }\end{array}$ & $\begin{array}{l}\text { Living longer, working longer? The } \\
\text { impact of subjective life expectancy } \\
\text { on retirement intentions and } \\
\text { behavior }\end{array}$ & Expectativa subjetiva de vida. \\
\hline $\begin{array}{l}\text { Shultz, Morton e } \\
\text { Werckerle (1998) }\end{array}$ & $\begin{array}{l}\text { The influence of push and pull } \\
\text { factors on voluntary early retirees, } \\
\text { retirement decision and adjustment }\end{array}$ & $\begin{array}{l}\text { Efeitos pull e push, status social, satisfação pessoal, status } \\
\text { financeiro. }\end{array}$ \\
\hline Gielen (2007) & $\begin{array}{l}\text { Working hours flexibility and older } \\
\text { workers labor supply }\end{array}$ & Flexibilidade de horário. \\
\hline $\begin{array}{l}\text { Charles e Decicca } \\
(2007)\end{array}$ & Hours flexibility and retirement & Controle do trabalho, flexibilidade de horário. \\
\hline $\begin{array}{l}\text { Menezes e França } \\
(2012)\end{array}$ & $\begin{array}{l}\text { Aposentar ou continuar } \\
\text { trabalhando? Fatores relevantes } \\
\text { na decisão da aposentadoria por } \\
\text { servidores públicos federais. }\end{array}$ & $\begin{array}{l}\text { Gênero, nível de escolaridade, saúde percebida, expectativa } \\
\text { subjetiva de vida, comprometimento com o trabalho, } \\
\text { percepção do trabalho, flexibilidade de horário, controle do } \\
\text { trabalho. }\end{array}$ \\
\hline
\end{tabular}

No que diz respeito à decisão de continuar a trabalhar ou de aposentar-se em definitivo, a pesquisa mais proeminente foi realizada por Kim e Feldman, na Universidade da Califórnia (UC), diante de sucessivos programas de aposentadoria oferecidos a acadêmicos na década de 90 . Os resultados revelaram a importância dos fatores biopsicossociais e do trabalho. De acordo com esses autores, idade, sexo, condição de saúde, condição socioeconômica, condição geral do parceiro e características do emprego poderiam reter os trabalhadores mais velhos por mais tempo no mercado de trabalho. O baixo salário e o fato de ser mais velho mostraram-se inversamente relacionados com a permanência no trabalho.

Quanto à decisão sobre o bridge employment e a aposentadoria definitiva, Kim e Feldman (2000) destacam que a condição de saúde, o status organizacional, ter o cônjuge ainda trabalhando e possuir dependentes financeiros são fatores que estão associados positivamente à decisão por esse tipo de transição (bridge employment). Assim, o fato de receber altos salários, de ter um pacote de benefícios completos e de ser mais jovem na época da aposentadoria influenciariam as atitudes frente à decisão de permanecer ativo e de optar pelo bridge employment. Por outro lado, se os trabalhadores mais velhos tiverem a saúde frágil ou doenças crônicas, não tiverem dependentes financeiros e cônjuges já aposentados, esses fatores os predisporiam a optar pela aposentadoria definitiva. Os autores também aventaram a hipótese de que o fato de se ter amigos no ambiente de trabalho, de receber um bom salário e de estar com idade para aposentar-se influenciam a decisão de aposentar-se ou de continuar trabalhando, quer isso envolva ou não o bridge employment. 
Zhan, Wang, Liu e Shultz (2009) argumentaram que a decisão da aposentadoria é influenciada por três níveis de variáveis.

O primeiro é a situação pessoal do trabalhador; o segundo está relacionado à organização na qual o indivíduo trabalha, e o terceiro nível envolve a sociedade e as relações pessoais e profissionais da pessoa.
Ulrich e Brott (2005) corroboraram os resultados de Kim e Feldman quanto à associação positiva da saúde com o bridge employment bem como quanto à associação negativa da idade com essa mesma decisão. Shultz, Morton e Werckerle (1998) analisaram o denominado efeito de puxar ou empurrar - efeitos pull (para dentro) e push (para fora), isto é, tanto os fatores positivos quanto os negativos que agem sobre a decisão da aposentadoria. A satisfação pessoal, a classe social e o status financeiro foram considerados por Shultz et al. como os principais preditores para a decisão da aposentadoria. Contudo, após essa decisão, os aspectos que forçaram a aposentadoria antecipada acabam por afetar a percepção de baixa condição de saúde e de satisfação quanto à vida. Outro preditor importante é o fato de ter recebido ou não orientação prévia na decisão da aposentadoria.

Beehr, Glazer, Nielson, e Farmer (2000), procurando determinar características relacionadas ao ambiente de trabalho e à vida em geral que atrairiam pessoas para a aposentadoria, desenvolveram um estudo quantitativo com 179 trabalhadores de uma instituição governamental (USA) e com suas esposas, com o objetivo de investigar quais preditores relacionados ao trabalho e à vida fora do trabalho influenciavam a decisão de aposentar-se. Os resultados mostraram que mais elementos da vida fora do trabalho (necessidade de cuidar de outra pessoa, idade obrigatória de aposentadoria, expectativas de trabalhar remuneradamente após a aposentadoria, expectativa de participar de atividades consideradas de crescimento trabalho voluntário, religião ou fazer cursos) foram preditores da época para a aposentadoria do que elementos do trabalho (estar cansado de trabalhar). Baseando-se nos resultados, os autores ressaltam que finanças mostrou-se um forte preditor da aposentadoria. Além disso, o fato de que a expectativa de desenvolver atividades consideradas de crescimento estava positivamente relacionada com a aposentadoria sugere que a oferta de cursos e de treinamentos no local de trabalho pode realmente dissuadir os funcionários de se aposentar.

Zhan, Wang, Liu e Shultz (2009) argumentaram que a decisão da aposentadoria é influenciada por três níveis de variáveis. O primeiro é a situação pessoal do trabalhador; o segundo está relacionado à organização na qual o indivíduo trabalha, e o terceiro nível envolve a sociedade e as relações pessoais e profissionais da pessoa. Esses mesmos autores reforçam os achados de Kim e Feldman quanto à importância da legislação, da carga horária, da estrutura da organização, do preconceito e da discriminação como fatores que influenciam a decisão da aposentadoria, e acrescentam a importância de os trabalhadores receberem orientação prévia para a decisão da aposentadoria.

Ulrich e Brott (2005) investigaram, por meio de um estudo qualitativo, as experiências na transição de trabalhadores aposentados que se integraram em empregos de tipo bridge. Os resultados demonstraram que a maior flexibilidade e controle sobre o trabalho estavam correlacionados ao desejo de permanecer ativo, seja postergando a aposentadoria, seja adotando outra forma de trabalho remunerado após a aposentadoria. Para esses autores, o bridge employment pode representar um novo começo, oferecendo a possibilidade de relações mais equilibradas na família, para o companheiro e para o lazer. Além disso, o fato de desempenhar atividades em seu próprio ritmo, com redução de carga horária e em ambiente familiar, são aspectos importantes para essa opção.

Wang, Zhan, Liu e Shultz (2008) incluíram três atributos individuais no modelo da decisão da aposentadoria que envolvem o bridge employment ou a aposentadoria definitiva, a saber: idade, condição financeira e saúde percebida. Outro aspecto relevante nessa 
decisão é a existência dos vínculos dos trabalhadores com o trabalho, tais como: convívio com os colegas, status coorporativo, viagens a trabalho e sentimento de utilidade. Shacklock e Brunetto (2005) também identificam a importância de práticas flexíveis de trabalho para manter os trabalhadores mais velhos na organização, assim como a influência de fatores intrínsecos. A motivação para o trabalho (intrínseco) pode influenciar um indivíduo a permanecer trabalhando ou a aposentar-se antecipadamente.

Wang, Adams, Beehr e Shultz (2009) propuseram um estudo que revê os aspectos que influenciam na decisão da aposentadoria, baseando-se em dados disponíveis no Instituto Nacional de Envelhecimento dos EUA. Foram apresentadas quatro grandes categorias de preditores da aposentadoria: i) atributos individuais, ii) variáveis psicológicas e atributos do trabalho, iii) variáveis relacionadas à família e iv) planejamento da aposentadoria. Os atributos individuais se configuram como a primeira categoria para o modelo de Wang et al., a qual englobou a idade, educação, saúde percebida e status financeiro; a segunda categoria considerou os atributos do trabalho, incluindo estresse e satisfação com o trabalho, a terceira considerou a família, englobando o status familiar e a qualidade desse relacionamento, e a quarta categoria, a presença ou a ausência do planejamento para a aposentadoria. Wang et al. concluíram que os aposentados mais jovens, com maior estudo, com melhor saúde, que sofrem menos estresse e maior satisfação no trabalho e que tenham pensado menos sobre a aposentadoria eram mais propensos a envolver-se no bridge employment do que a aposentar-se definitivamente.

Zappalà, Depolo, Fraccaroli, Guglielmi e Sarchielli (2008) desenvolveram um estudo que buscou investigar as preferências individuais de aposentadoria antecipada ou tardia. Um questionário foi submetido a 275 trabalhadores italianos, incluindo variáveis pessoais (e.g., idade, renda), variáveis do trabalho e organizacionais (e.g., importância do trabalho, demandas e controle do trabalho) e variáveis de aposentadoria (nível de informação sobre pensões e atitudes para aposentadoria). Foram realizadas análises de regressão múltiplas hierárquicas para testar o impacto de tais variáveis sobre a preferência para a aposentadoria precoce ou tardia, e os resultados mostraram uma preferência significativa para aposentar-se, em média, três anos antes da idade esperada. As únicas variáveis demográficas que se correlacionaram com o critério de preferência para aposentadoria (antecipada ou tardia) foram a idade cronológica e a percepção atual de uma situação financeira adequada. As variáveis do trabalho (importância do trabalho, baixo nível de demandas do trabalho e políticas empresariais de envelhecimento), atitudes negativas para aposentadoria e baixo nível de informação sobre pensões foram relacionadas à preferência pela aposentadoria tardia.

Solinge e Henkens (2009) assinalam que a expectativa subjetiva de vida deve ser considerada na decisão da aposentadoria. Essa expectativa é medida pela percepção dos indivíduos sobre o tempo de vida que imaginam que terão pela frente, considerando a longevidade de sua família, principalmente a dos pais, os fatores de risco conhecidos (doenças pré-existentes) e a condição socioeconômica. O estudo desses autores teve por objetivo testar se, em um grupo de trabalhadores holandeses mais velhos, o planejamento da aposentadoria variava de acordo com as expectativas de sobrevivência, considerando duas questões: i) Qual é a expectativa de vida restante e quais são os fatores que influenciam a expectativa subjetiva?, ii) Os trabalhadores que acreditam ter maior expectativa subjetiva de vida estão mais inclinados a aposentar-se mais tarde do que aqueles que têm menor expectativa subjetiva de vida? 
$\mathrm{Na}$ medida em que os trabalhadores conseguem vislumbrar sua expectativa subjetiva de vida, é possível planejar melhor sua aposentadoria (Solinge e Henkens, 2009). A intenção ou a atitude do trabalhador antes da aposentadoria pode ser diferente do comportamento no momento da decisão, e isso pode acorrer porque muitos trabalhadores mais velhos têm pouco controle sobre o momento em que vão aposentar-se. Outro motivo é que nem sempre a aposentadoria pode ser voluntária, como nos casos em que o trabalhador é acometido por alguma doença incapacitante ou vê-se obrigado a cuidar do parceiro doente ou inválido. Tais resultados devem ser considerados sob o ponto de vista das políticas públicas norteadoras dos programas de preparação para a aposentadoria e na oferta de projetos de educação ao longo da vida, levando-se em conta outras atividades além do trabalho, tais como as atividades físicas, de lazer, culturais, educação e voluntariado (França, 2011).

O paradigma de associar o horizonte de vida do indivíduo ao seu comportamento não é novo. A expectativa subjetiva de vida tem sido considerada em relação a vários aspectos do interesse humano, entre eles o investimento em capital, poupança e consumo e o comportamento relativo à saúde. Contudo, Solinge e Henkens foram os primeiros a testar a correlação existente entre a percepção da expectativa de vida subjetiva e a decisão da aposentadoria. Os resultados demonstraram que os indivíduos que possuem maior expectativa subjetiva de vida - independentemente de qualquer situação prévia na sua consideração - estão mais propensos a trabalhar por mais tempo, postergando a aposentadoria.

Menezes e França (2012) realizaram o primeiro estudo brasileiro sobre os preditores da decisão da aposentadoria com 148 servidores públicos federais em uma instituição de tecnologia. A influência dos aspectos como idade, saúde percebida, expectativa subjetiva de vida, comprometimento com a carreira, percepção no trabalho, flexibilidade no horário e controle do trabalho foram testados em função dessa decisão. A idade e a saúde foram considerados aspectos relevantes para a continuidade do trabalhador (na mesma instituição ou não) e para a aposentadoria definitiva, podendo, de acordo com sua significância, ser explicada como fator pull, quando a idade for menor e quando a percepção da saúde (continuidade do trabalho) for positiva, e push, quando a idade for maior e a percepção da saúde for negativa (aposentadoria definitiva).

\section{Discussão e conclusões}

Qual síntese se pode fazer dos estudos apresentados nas seções anteriores, e como eles respondem ao objetivo deste artigo, relacionado à identificação de fatores preditivos da decisão pela aposentadoria?

Em primeiro lugar, esses estudos enfatizam o caráter multideterminado desse fenômeno. Como consequência, assume-se que diversas classes de variáveis ou preditores atuam na decisão pela aposentadoria. Em segundo lugar, os estudos aqui apresentados compartilham a premissa de que a decisão da aposentadoria pode ter, como desfecho, a decisão de aposentar-se em definitivo, a de permanecer no mesmo trabalho/organização ou então a de adotar um regime diferenciado de trabalho, mais flexível e eventualmente diferente daquele em que se trabalhava antes de se aposentar - conhecido como bridge employment. Este último condiz não apenas com mudanças nas preferências pessoais em termos de carreira e estilo de vida mas é também um reflexo das profundas transformações pelas quais passou o trabalho nas últimas décadas, no sentido de que hoje 
é possível constatar-se a convivência de distintas formas de trabalhar, que permitem, em tese, maior flexibilidade e autonomia às pessoas.

Uma vez que os preditores já foram apresentados na seção anterior, aqui cabe apenas um esforço de síntese dos aspectos mais críticos para a discussão desse tema. No que diz respeito aos preditores relacionados à decisão de permanência na organização, por exemplo, chamam a atenção aqueles relativos à percepção de sentido e de importância no trabalho, à percepção de autonomia e de flexibilidade, à existência de treinamentos e cursos e às políticas empresariais voltadas para $\mathrm{o}$ envelhecimento. Diversos desses preditores se aplicam igualmente à decisão pelo bridge employment, especificamente à flexibilidade de horário, à possibilidade de maior controle do trabalho implicada na autonomia concedida ao profissional mais velho e à satisfação e à importância atribuída ao trabalho. Em ambos os tipos de decisão, portanto, questões relativas ao sentido do trabalho, à percepção de autonomia e de investimento por parte das organizações (na forma de treinamentos, de condições adequadas de trabalho e de programas voltados para questões de envelhecimento) e à percepção de equilíbrio entre vida pessoal e profissional desempenham papel decisivo na manutenção do desejo de permanecer no mundo do trabalho.

Quanto aos preditores que explicariam a decisão pela aposentadoria definitiva, encontramos aspectos, em muitos casos, inversos aos destacados acima. Assim, notase que altos níveis de stress no trabalho, carga excessiva de atividades, relacionamentos pobres na organização e baixa motivação para o trabalho podem predizer a decisão pela saída definitiva do mundo do trabalho.
Outros fatores, tanto de natureza pessoal quanto familiar, também influenciam nessa decisão, como o desejo de participar de atividades que não o trabalho (voluntariado, religião, fazer cursos, etc.), a idade muito avançada, menor nível educacional, saúde mais frágil e a necessidade de cuidar de outra pessoa (cônjuge, por exemplo).

A questão que se coloca neste ponto é como esses achados poderiam dialogar com a realidade brasileira. Poderiam eles ser transpostos para explicar processos de tomada de decisão em nosso contexto cultural, econômico, social? Ou tais modelos seriam explicações gerais (transculturais, universais) sobre a decisão de aposentar-se? Mesmo sem esgotar essas questões, algumas respostas podem ser esboçadas com o intuito de fomentar o debate.

Primeiramente, é preciso considerar que o estado da pesquisa sobre aposentadoria no Brasil, quando vista da Psicologia, ainda tem muitos desafios a superar, especificamente no que diz respeito à abrangência dos estudos. Não obstante, notam-se esforços da parte de diversos pesquisadores no sentido da construção de conhecimento sobre essa temática.

Além das já citadas ao longo deste artigo, merecem ainda destaque algumas contribuições adicionais, porém, é importante destacar que, embora esses estudos não tenham sido planejados para responder diretamente às pesquisas estrangeiras aqui relatadas, especialmente porque muitos deles foram conduzidos em perspectiva qualitativa, eles permitem algumas interações com aquelas pesquisas. O estudo de Romanini, Xavier e Kovaleski (2005), por exemplo, confirma a importância do status social oferecido pelo trabalho e seu impacto no adiamento da aposentadoria, concebida como o fim da atividade laborativa. 
Similarmente, Bressan, Mafra, França e Loretto (2012) observam que o envolvimento e a satisfação com o trabalho e a organização são fatores que dificultavam o desligamento para a aposentadoria dos participantes de seu estudo (servidores públicos). A investigação de Cruz (2011) verificou que a aposentadoria era adiada por razões financeiras, de manutenção do salário (também servidores públicos). O trabalho de Cintra, Ribeiro e Andrade (2010) com aposentados do setor calçadista demonstrou que o retorno ao trabalho para essas pessoas estava associado à necessidade de complementar o baixo valor da aposentadoria, por eles também representada como uma oportunidade de ampliar os vínculos sociais e de vivenciar o trabalho de maneira mais leve, com maior autonomia e flexibilidade.

O trabalho de Khoury, Ferreira, Souza, Matos e Barbagelata-Góes (2010) aponta que, para os aposentados pesquisados, a principal razão para voltar ao trabalho era a necessidade de sentir-se produtivo, demonstrando, com isso, a importância do trabalho na constituição da identidade, e o trabalho de Moreira (2011), conduzido com seis professores universitários, mostra que a aposentadoria não é entendida como o fim das atividades profissionais, mas como um benefício desvinculado da velhice. Com respeito ao trabalho, os participantes revelam satisfação pessoal, crescimento e aprendizagem, além do sentimento de liberdade, de inserção e de contribuição social.

Já os resultados da pesquisa conduzida por Menezes e França corroboram os achados de Kim e Feldman, Ulrich e Brott, Wang, Adams, Beehr e Shultz, Charles e Decicca (2007) e Gielen (2007) no que diz respeito à percepção do trabalho, à flexibilidade de horário e ao controle do trabalho como dotados de maior carga preditiva para a decisão pelo bridge employment. Contudo, as variáveis comprometimento com o trabalho e expectativa subjetiva de vida, assinaladas anteriormente por Blau (1985) e por Solinge e Henkens, respectivamente, não foram confirmadas como preditores positivos para a postergação da aposentadoria.

Considerando a diversidade dos estudos brasileiros acima relatados (quantitativos, qualitativos e mistos, com participantes de diversas categorias ocupacionais e características psicossociais), pode-se dizer que a reflexão sobre a plausibilidade da transposição de estudos internacionais sobre decisões de aposentadoria à nossa realidade deve ser colocada em perspectiva. É necessário, em primeiro lugar, ampliar a base de estudos empíricos nacionais para que se possa gerar massa crítica capaz de permitir uma discussão substanciada acerca de modelos que são aderentes ou não à nossa realidade. Inobstante essa situação, parece que algumas características comuns dos estudos internacionais aqui relatados podem servir de estímulo àquela ampliação, em particular, a consideração de múltiplos níveis de análises, cada um deles com suas classes de variáveis. Assim, os pesquisadores podem considerar, em seus estudos, aspectos relacionados: i) ao próprio trabalho (seu significado, sua importância, seu conteúdo, etc.), ii) à organização (políticas internas, gestão de recursos humanos, arranjos de trabalho, níveis de autonomia, etc.), iv) a fatores sociodemográficos (idade, gênero, condição de saúde, renda familiar anual e nível de educação), v) a aspectos não relacionados ao trabalho (família e demais esferas de vida) e vi) a fatores individuais (personalidade, saúde, nível financeiro, níveis de motivação, etc.). Considerando ser o Brasil o quinto país com maior número de idosos do mundo, e levando em conta sua diversidade cultural, geográfica e socioeconômica, resta 
aos pesquisadores criarem estratégias de pesquisas para subsidiar uma reflexão crítica acerca das características de cada uma dessas dimensões de análise.

Por fim, encerra-se este artigo com a apresentação de alguns desafios para a gestão da aposentadoria na atualidade, considerando as informações aqui trabalhadas. Em particular, o maior deles parece ser a tomada de consciência de que é necessário manter os trabalhadores por mais tempo trabalhando satisfeitos, isso porque, considerando a expectativa projetada de vida, as pessoas ainda devem viver décadas após a aposentadoria. A questão que se coloca é: o que fazer com as pessoas que desejarem continuar no trabalho após a decisão de aposentar-se? Se é certo que o Brasil é um país de contradições, e que muitas pessoas podem desejar aposentarse em definitivo, pois seus trabalhos atuais são desprovidos de estímulos intrínsecos ou então executados em condições precárias e extenuantes, muitas outras, especialmente em certos estratos sociais, podem preferir continuar a trabalhar, seja ou não no formato de bridge employment.

Se dois preditores-chave para o desejo de continuar no trabalho, conforme citado neste artigo, são a flexibilidade e a autonomia (o controle sobre o próprio trabalho), então o desafio que se volta para nossa realidade é o de como fomentar a existência dessas duas características nos contextos de trabalho. De um lado, isso esbarra em questões de legislação. No Brasil, são ainda muito raros os empregos em tempo parcial. Em outros países, de onde provieram a maioria dos estudos aqui reportados, arranjos alternativos de trabalho são mais comuns e têm respaldo institucional/legal, portanto, o cenário do bridge employment deve ser relativizado quando pensamos na realidade brasileira, o que pode, inclusive, servir como uma limitação na transposição de que se tratou antes.

Nessa mesma linha de dificuldades insere-se a abertura do próprio negócio, a possibilidade de empreender após a aposentadoria. Como no caso do emprego em tempo parcial, aqui também há diversas dificuldades e desincentivos, sejam de ordem governamental, sejam econômicas. Em um ambiente institucional mais favorável à autoiniciativa, é possível que haja mais pessoas predispostas a permanecer na atividade profissional. No caso do Brasil, em que pesem mudanças recentes, o ambiente empreendedor ainda é fortemente onerado, e, assim, essa circunstância também pode agir como um fator moderador ou atenuante dos preditores relacionados ao bridge employment. Dificuldades equivalentes poderiam ser citadas para o caso daqueles trabalhadores que decidem continuar no trabalho na mesma organização.

Por fim, é fundamental que a sociedade, e seus diversos atores (responsáveis pela gestão de recursos humanos, sindicatos, instituições públicas, organizações, etc.), discutam sobre esses e outros fatores restritivos ao desejo de pessoas mais velhas, já aposentadas ou em vistas de fazê-lo continuarem a trabalhar, como, por exemplo, o preconceito existente contra a idade (ageismo) dentro de uma política de inclusão. E, mesmo para aquelas que optarem por deixar em definitivo o mercado de trabalho, que possam desfrutar de um ambiente favorável ao desenvolvimento de qualidade de vida e de outras potencialidades não realizadas durante o tempo regular de trabalho que inclusive poderiam ser estimuladas em um programa de preparação para a aposentadoria. Com isso, esbarramos em problemas que transcendem a questão 
estrita da aposentadoria e que dizem respeito ao lugar do idoso em nossa sociedade. Afinal, a decisão de aposentarse, e as consequências dela derivadas, não se dão em um vácuo cultural. Trata-se, dessa forma, de um poderoso desafio lançado aos pesquisadores da área da Psicologia.

Lucia Helena de Freitas Pinho França

Doutora em Psicologia pela The University Of Aucklande e docente da Universidade Salgado de Oliveira, Niterói - RJ - Brasil.

E-mail: luciafranca@luciafranca.com

\section{Pedro F. Bendassolli}

Doutor em Psicologia Social do Trabalho pela Universidade de São Paulo e docente da Universidade Federal do Rio Grande do Norte, Natal - RN - Brasil.

E-mail: pbendassolli@gmail.com

\section{Gustavo Silva Menezes}

Doutorando em Psicologia pela Universidade Salgado de Oliveira, Niterói - RJ - Brasil.

E-mail: gustavo.menezes@int.gov.br

\section{Luciani Soares Silva Macedo}

Mestranda em Psicologia pela Universidade Federal do Rio Grande do Norte e servidora da Pró-Reitoria de Gestão de Pessoas da Universidade Federal do Rio Grande do Norte, Natal - RN - Brasil.

E-mail: lucianissm@uol.com.br"

\section{Endereço para envio de correspondência:}

Programa de Pós-Graduação em Psicologia da Universidade Salgado de Oliveira - UNIVERSO. CEP: 24020-420. Niterói, RJ.

Recebido 17/12/2011, 1ㅍ- Reformulação 05/12/2012, Aprovado 11/04/2013. 
Adler, G., \& Hilber, D. (2009). Industry hiring patterns of older workers. Research on Ageing, 31(1), 69-88.

Beehr, T. A., Glazer, S., Nielson, N. L., \& Farmer, S. J. (2000). Work and nonwork predictors of employees' retirement ages. Journal of Vocational Behavior 57, 206-225. doi:10.1006/ jube.1999.1736

Blau, G. (1985). The measurement and prediction of career commitment. Journal of occupational Psychology, 58(4), 277-288.

Bressan, M. A. L. C, Mafra, S. C. T, França, L. H. F. P., Melo, M. S. S., \& Loretto, M. D. S. (2012). Trabalho versus aposentadoria: desvendando sentidos e significados. Oikos: Revista Brasileira de Economia Doméstica, 23(1), 226-250.

Camarano, A. A. (2001). O idoso brasileiro no mercado de trabalho. Rio de Janeiro: IPEA.

Charles, K. K., \& Decicca, P. (2007). Hours flexibility and retirement. Economy Inquiry, 45(2), 251-267. doi:10.1111/ j.1465-7295.2006.00009.x

Cintra, T. S., Ribeiro, D. de F., \& Andrade, A. dos S. (2010). O cotidiano de aposentados que continuam trabalhando de maneira informal na indústria calçadista: percepções sobre a aposentadoria e o trabalho atual. Cadernos de Psicologia Social do Trabalho, 13(2), 277-287. Recuperado em 27 de maio, 2012 de http://www.revistasusp.sibi.usp.br/ scielo.php?pid =S1516-37172010000200009\&script $=$ sci_ arttext\&tlng=es

Cruz, M. A. G. da. (2011). Adiando a aposentadoria: um estudo sobre os fatores que levam servidores federais a adiar a aposentadoria em uma instituição de pesquisa (Dissertação de Mestrado). Universidade de Taubaté, Taubaté, SP. Recuperado em 23 abril, 2012 de http://mtc-m19.sid. inpe.br/col/sid.inpe.br/mtc-m19/2011/05.02.13.44/doc/ publicacao.pdf

Debetir, E., \& Monteiro, L. A. S. (1999). Qualidade de vida e preparação para a aposentadoria na Universidade Federal de Santa Catarina, Brasil. In XXIII Encontro da Associação Nacional dos Programas de Pós-Graduação em Administração - ENANPAD.

Feldman, D. C. (1994). The decision to retire early: A review and conceptualization. Academy of Management Review, 19, 285-311.

Feldman, D., \& Beehr, T. (2011). A three-phase model of retirement decision making. American Psychologist, 66(3), 193-203. 
Flynn, M. (2010). Who would delay retirement? Typologies of older workers. Personnel Review, 39(3), 308-324. doi:10.1108/00483481011030511.

França, L. H. (2008). O desafio da aposentadoria: o exemplo dos executivos do Brasil e da Nova Zelândia. Rio de Janeiro: Rocco.

França, L. H. (2011). O envelhecimento populacional e seu reflexo nas organizações: a importância da educação ao longo da vida, Boletim Técnico do Senac, 37(2), 49-59.

França, L. (2012). Envelhecimento dos trabalhadores nas organizações: estamos preparados? In L. França \& D. Stepansky (Orgs.), Propostas multidisciplinares para o bem-estar na aposentadoria (pp. 25-52). Rio de Janeiro: Quarter/FAPERJ.

Giatti. L., \& Barreto, S. M. (2003). Saúde, trabalho e envelhecimento no Brasil. Cadernos Saúde Pública, 19(3), 759-771.

Gielen, A. C. (2007). Working hours flexibility and older workers labor supply. Iza Discussion Paper no 2946. Departament of Economics, Tilburg University, Netherlands.

Instituto Brasileiro de Geografia e Estatística - IBGE. (2008). Projeção da população do Brasil por sexo e idade para o período 1980-2050. Diretoria de Pesquisas, Coordenação de População e Indicadores Sociais.

Instituto Brasileiro de Geografia e Estatística- IBGE. (2012). Pesquisa nacional por amostra de domicilio (PNAD 2011). (Apresentação em ppt pela Comunicação do IBGE em 21/09/2012). Recuperado em 23 de março, 2013, de http://www.ibge.gov.br/home/presidencia/ noticias/imprensa/ppts/00000010135709212012572 220530659.pdf

Kim, S., \& Feldman, D. (2000). Working in retirement: The antecedents of bridge employment and its consequences for quality of life in retirement. Academy of Management Journal, 43(6), 1195-1210.

Khoury, H. T., Ferreira, A., Souza, R., Matos, A., \& Barbagelata-Góes, S. (2010). Por que os aposentados retornam ao trabalho? Revista Kairós de Gerontologia, 13(1), 147-165.

Menezes, G. S., \& França, L. H. (2012). Preditores da decisão da aposentadoria por servidores públicos federais. Psicologia: Organizações e Trabalho, 12(3), 49-62.

Moreira, J. (2011). Imaginários sobre aposentadoria, trabalho, velhice: estudo de caso com professores universitários. Psicologia em Estudo, 16(4), 541-550. Recuperado em 2 de abril, 2013 de http://www.scielo.br/scielo. php?pid $=$ S1413-73722011000400005\&script $=$ sci arttext

Organização das Nações Unidas. (2009). World Population Ageing 2009. New York. Recuperado em 27 março, 2013 de http://www.un.org/esa/population/publications/ WPA2009/WPA2009 WorkingPaper.pdf

Pengcharoen, C., \& Shultz, K. S. (2010). The influences on bridge employment decisions. International Journal of Manpower, 31(3), 322-336. do 10.1108/01437721011050602

Rhum, C. (1990). Bridge jobs and partial retirement. Journal of Labor Economics, 8(4), 482-501.
Rodrigues, N. C. (2000). Aspectos sociais da aposentadoria. In C. R. Schons \& L. S. Palma (Org.), Conversando com Nara Costa Rodrigues: sobre gerontologia social (pp. 21-25). Passo Fundo, RS: UPF.

Romanini, D. P., Xavier, A. A. P., \& Kovaleski, J. L. (2005). Aposentadoria: período de transformações e preparação. Revista Gestão Industrial, 1(3), 93-102.

Ruhm, C. (1990). Career jobs, bridge employment, and retirement. In P. Doeringer (Ed.), Bridges to retirement (pp. 92-110). Ithaca, NY: ILR Press.

Shacklock, K., \& Brunetto, Y. (2005). Employees' perceptions of the factors affecting their decisions to retire. International Journal of Organizational Behaviour, 10(5), 740-756.

Shultz, K. S., Morton, K., \& Werckerle, J. R. (1998). The influence of push and pull factors on voluntary early retirees, retirement decision and adjustment. Journal of Vocational Behavior, 53(1), 45-57.

Solinge, H. V., \& Henkens, K. (2009). Living longer, working longer? The impact of subjective life expectancy on retirement intentions and behavior. European Journal of Public Health, 19(6), 1-5.

Stepansky, D. V., \& França, L. H. F. (2008). Trabalho e vida pessoal: o equilíbrio necessário. Boletim Técnico do SENAC, $34(1), 64-71$.

Ulrich, L., \& Brott, P. (2005). Older workers and bridge employment: Redefining retirement. Journal of Employment Counseling, 42(4), 159-170.

Fundo de População das Nações Unidas - UNFPA. (2012). Envelhecimento no século XXI: celebração e desafio. Recuperado em 25 de abril, 2012 de http://www.unfpa.org/ webdav/site/global/shared/documents/publications/2012/ Portuguese-Exec-Summary.pdf

Wang, M., Zhan, Y., Liu, S., \& Shultz, K. (2008). Antecedents of bridge employment: A longitudinal investigation. Journal of Applied Psychology, 93(4), 818-830.

Wang, M., Adams, G. A., Beehr, T. A., \& Shultz, K. S. (2009). Bridge employment and retirement: Issues and opportunities during the latter part of one's career. In S. G. Baugh \& S. E. Sullivan (Eds.), Maintaining focus, energy, and options over the career (pp.135-162). Charlotte, NC: Information Age Publishing, Inc.

Wang, M., \& Shultz, K. S. (2010). Employee retirement: A review and recommendations for future investigation. Journal of Management, 36(1), 172-206. doi:10.1177/0149206309347957

Zappalà, S., Depolo, M., Fraccaroli, F., Guglielmi, D., \& Sarchielli, G. (2008). Postponing job retirement? Psychosocial influences on the preference for early or late retirement. Career Development International, 13(2), 150167. doi:10.1108/13620430810860558

Zhan, Y., Wang, M., Liu, S., \& Shultz, K. (2009). Bridge employment and retirees' health: A longitudinal investigation. Journal of Occupational Health Psychology, 14(4), 374-389. 